\title{
ENFERMEIRA - A CONSTRUÇÃO DE UM MODELO DE COMPORTAMENTO A PARTIR DOS DISCURSOS MÉDICOS DO INÍCIO DO SÉCULO
}

\author{
Maria Itayra Coelho de Souza Padilha* \\ Vera Regina Salles Sobral ** \\ Lúcia Maria Ramalho Leite*** \\ Maria Angélica A. Peres**** \\ Andreia C. de Araújo ****
}

PADILHA, M.I.C.S.; SOBRAL, V.R.S.; LEITE, L.M.R.; PERES, M.A.A.; ARAÚJO, A.C. Enfermeira - a construção de um modelo de comportamento a partir dos discursos médicos do início do século. Rev.latino-am.enfermagem, Ribeirão Preto, v.5, n. 4, p. 25-33, outubro 1997.

O objetivo é traçar um paralelo entre o conteúdo dos discursos médicos e o comportamento esperado e estereotipado das enfermeiras do início do século. É uma abordagem histórico-social que utilizou como fontes os discursos médicos e de enfermeiras proferidos nas escolas de enfermagem e de medicina. A análise dos discursos médicos comparada aos discursos das enfermeiras refletem a formação de uma mentalidade intrinsecamente modelada e docilizada pelo poder médico que as desejava santas e subservientes.

UNITERMOS: enfermagem, história, santa casa de misericórdia do Rio de Janeiro

\section{CONSIDERAÇÕES INICIAIS}

A prática assistencial de enfermagem atual recebeu uma herança histórica decorrente de ser uma profissão eminentemente feminina, que lhe confere um caráter não linear, repleto de contradições e influenciando de forma decisiva a sua ação, necessitando portanto, ser compreendida.

O mais conhecido trabalho sobre a história da enfermagem foi escrito por PAIXÃO (1979) que, mediante pesquisa bibliográfica, faz um retrospecto da enfermagem desde a idade antiga até o século XX com ênfase na influência religiosa sobre a profissão. Citado na maioria dos estudos sobre o assunto, vem servindo de livro texto nos cursos de graduação em enfermagem de todo o país.

Estudos mais críticos foram publicados a partir da década de 80, com uma preocupação em compreender a enfermagem como parte de um processo histórico, social, cultural, político e educativo, analisando e denunciando de modo mais nítido a conduta humilde, conformista e dócil das enfermeiras nas relações com quem representa o poder, contrário a sua conduta autoritária, frequentemente assumida nas relações com os demais elementos da equipe de enfermagem. Não obstante, grande parte desses estudos é restrita à enfermagem "nightingaleana", a qual só se tornou realidade no Brasil, com a criação no Rio de Janeiro, da Escola de Enfermeiras do Departamento Nacional de Saúde Pública, em 1923*****.

Acreditamos, portanto, que existe uma história para ser contada que ainda não foi desvendada. Este estudo pretende contribuir para diminuir o vácuo historiográfico e ampliar a compreensão da enfermagem brasileira a partir da análise do conteúdo dos discursos médicos e do comportamento estereotipado das enfermeiras do início do século e que permanecem até hoje no ideário da enfermagem.

Trata-se de um estudo de natureza sócio-histórica, para a qual utilizaremos as idéias preconizadas por Michel

\footnotetext{
* Professora Assistente do Depto de Metodologia de Enfermagem da EEAN/UFRJ. Livre-Docente em Exercício de Enfermagem pela UNIRIO. Doutoranda pela EEAN/UFRJ. Pesquisadora do CNPq

** Professora Adjunta do Depto de Enfermagem Materno-Infantil e Psiquiatria da UFF/RJ. Doutora em Enfermagem pela EEAN/ UFRJ. Pesquisadora do CNPq

*** Historiadora, Bolsista de Apoio Técnico - CNPq

***** Alunas de Graduação do Curso de Enfermagem da EEAN/UFRJ. Bolsistas de Iniciação Científica - CNPq

***** O curso foi organizado pela Enfermeira americana Clara Louise Kieninger, a qual introduziu o modelo "nightingaleano" de enfermagem no Brasil. Em 1925 a escola foi denominada Escola de Enfermeiras Dona Ana Neri. ALCÂNTARA, G. A enfermagem moderna como categoria profissional: Obstáculos à sua expansão na sociedade brasileira. Ribeirão Preto, USP/EERP, 1966
} 
FOUCAULT* para a análise e discussão dos documentos à luz da análise genealógica. A escolha se deu porque este é um estudo dos grupos humanos no seu espaço temporal com a preocupação de discutir os variados aspectos do cotidiano e as manifestações de poder que ocorrem nas relações sociais.

A construção da história de vida social tem sido em maior ou menor grau atravessada por conflitos, vitórias e derrotas que, mais do que meros "acidentes de percurso" no caminho do equilíbrio, são, na verdade, elementos constitutivos e essenciais da vida social.

A história da enfermagem é uma história de conflitos, (mais visíveis ou menos visíveis) na disputa e discussão sobre as relações de poder e esses embates é que estão na raiz das transformações sociais que pretendemos investigar.

A história permite que se trace uma ponte entre o presente e o futuro de modo que aos poucos, na medida da produção desse conhecimento novo, possa se prever a minúcia do vir a ser de mulheres diferentes daquelas que foram ideologicamente determinadas pela cultura patriarcal (DIAS, 1994).

Neste estudo, os dados provêm de fontes primárias e secundárias. As fontes primárias correspondem a discursos proferidos pelas Enfermeiras norteamericanas Clara Louise Kieninger e Ethel Parsons, responsáveis pela organização e implantação do modelo "nigthingaleano" de enfermagem no Brasil; discursos médicos sobre as alunas do Curso de enfermagem da Escola de Enfermeiras do Departamento Nacional de Saúde Pública, atual Escola Anna Nery; e discursos médicos contidos em livros sobre a História da saúde e da medicina no Brasil escritos na primeira metade do nosso século. As fontes secundárias correspondem aos livros de História do Brasil e da Saúde, a teses e estudos pertinentes às práticas de Saúde e de enfermagem no Brasil.

As diferentes fontes primárias serão submetidas à crítica interna e externa, a fim de verificar a veracidade do conteúdo do documento. A crítica interna ou crítica de credibilidade tem por finalidade analisar o conteúdo do trabalho do autor em termos de originalidade e confiabilidade. Na crítica externa o pesquisador avalia se o texto é original ou foi alterado ao longo do tempo (SALMON, 1979).

Será utilizada a análise de discurso enunciada por Michel Foucault. Este considera os discursos como uma dispersão, isto é, como sendo formados por elementos que não estão ligados por nenhum princípio de unidade. Cabe à análise do discurso descrever essa dispersão, buscando o estabelecimento de regras capazes de reger a formação dos discursos. Define o discurso como um conjunto de enunciados que remetem a uma mesma formação discursiva "um discurso é um conjunto de enunciados que tem seus princípios de regularidade em uma mesma formação discursiva" (FOUCAULT, 1982).

\section{A ORDEM DE ENFERMAGEM E A ORDEM MÉDICA}

O desenvolvimento do trabalho da enfermagem e demais profissões da área de saúde, bem como a forma como as relações de saber/poder se estabelecem entre elas, foi construído a partir da transformação do sistema de poder na sociedade, mas também no interior do hospital.

Até meados do século XVIII, os religiosos detinham o poder institucional. Porém, a partir do momento em que o hospital é concebido como um instrumento de cura e a distribuição do espaço torna-se um instrumento terapêutico, o médico passa a ser o principal responsável pela organização hospitalar, e a comunidade religiosa é banida para que o espaço possa ser organizado medicamente (FOUCAULT, 1982).

O médico confia aos religiosos um papel determinado, mas subordinado; aparece então a categoria do "enfermeiro", e o hospital bem "disciplinado" constitui-se o local adequado da "disciplina médica". Esta disciplinarização permite ao médico curar os doentes e controlar o cotidiano dos demais profissionais, além de determinar o tipo de comportamento esperado no espaço hospitalar.

FOUCAUT (1982, p. 111) comprova este dado acrescentando que

\begin{abstract}
“... com a aplicação da disciplina no espaço médico e pelo fato de que se pode isolar cada indivíduo, instalá-lo em uma cama, prescreverthe uma dieta, etc... pretende-se chegar a uma medicina individualizante. Com efeito, é o indivíduo que será observado, vigiado, conhecido, curado. $O$ indivíduo surge como objeto de saber da prática médica”.
\end{abstract}

Desde Florence Nightingale a disciplina, a obediência e a subserviência na enfermagem são consideradas como parte indissociável do exercício diário, não apenas no que concerne às ações assistenciais como também às relações entre $\mathrm{a}(\mathrm{o})$ enfermeira(o) e o médico, a equipe de enfermagem e a administração hospitalar.

* FOUCAUlT, M. Microfísica do Poder. $3^{\mathrm{a}}$ ed. Rio de Janeiro, Graal, 1982. Cap. 11 e 12. A arqueologia do Saber. $4^{\mathrm{a}}$ ed. Rio de Janeiro: Forense Universitária, 1995. Cap. 2 e 3 
Florence Nightingale é a precursora da Enfermagem moderna em todo o mundo, obtendo projeção maior a partir de sua participação como voluntária na Guerra da Criméia*, em 1854, quando com 38 mulheres (irmãs anglicanas e católicas) organizou um hospital para 4000 soldados internos, baixando a mortalidade local de $40 \%$ para $2 \%$. Com o prêmio recebido do governo inglês por este trabalho, fundou a primeira escola de enfermagem no Hospital St. Thomas - Londres, em 24 de junho de 1860.

O momento em que Nightingale cria a profissão de enfermagem na Inglaterra coincide com as transformações evidenciadas por Foucault no ambiente hospitalar, estabelecendo o vínculo entre o saber de enfermagem e o saber médico, numa situação de subordinação. Acreditamos que o fato desta relação se estabelecer (na maioria das vezes) entre gêneros diferentes, com a predominância específica do gênero feminino para a enfermagem e até bem pouco tempo do gênero masculino para a medicina, tem um peso significativo na forma como se relacionam esses profissionais.

Atualmente, na prática profissional, observamos, muitas vezes, as atitudes da enfermeira como de obediência e submissão às "ordens médicas"**, ausência de uma atitude questionadora e científica, bem como dificuldade ou quase inexistência de cooperação entre elementos da equipe multiprofissional. Em contrapartida, no que se refere às relações de poder da enfermeira junto à equipe de enfermagem, verifica-se uma alternância de papéis, isto é, estas assumem atitudes de autoridade, responsabilidade e exigência no cumprimento dos deveres, semelhantes àquelas dos médicos. Com relação aos sujeitos do cuidado, a enfermeira, a equipe de enfermagem e os demais elementos da equipe de saúde não permitem qualquer discussão diante do cuidado que está sendo prestado. Esses devem obedecer cegamente as ordens de todos e as normas e rotinas da instituição, sob o risco de serem chamados de "rebeldes". E nos questionamos de que decorrem essas atitudes? Do fato de ser mulher historicamente submetida ao poder masculino ou a algo específico da profissão?

As mulheres aparecem desenvolvendo ações de cuidado aos doentes no trabalho caritativo das religiosas, das parteiras leigas, provedoras de saúde à família e como voluntárias na assistência aos doentes, como foi o caso no Brasil de Francisca de Sande e Anna Nery***. Desde meados do século passado, quando as irmãs de caridade assumem a direção dos serviços hospitalares e também os cuidados de enfermagem da Santa Casa de Misericórdia do Rio de Janeiro, as ações de enfermagem no Brasil passam a ser institucionalizadas e modeladas pelo espírito de religiosidade feminina****.

As irmãs de caridade assumiram a responsabilidade por toda a assistência prestada, isto é, ficavam no comando das enfermarias para determinar, supervisionar e executar cuidados de enfermagem que a sua condição de irmãs de caridade permitia. A assistência de enfermagem se resumia em dar o remédio na hora certa, cuidar do asseio, fazer companhia e auxiliar o paciente na ocasião das necessidades e de um possível banho, limpar o quarto e os dejetos dos pacientes e cuidar dos mortos. Também auxiliavam os médicos nos curativos ou outros cuidados que não era "decente"***** para as irmãs de caridade fazerem.

No cotidiano das enfermeiras a decência pode ser um detalhe focalizado a partir do ponto de vista judaico-cristão em que a virtude era quase sinônimo de honra, o bem maior de todas as mulheres, principalmente das religiosas e castas e consta como estatuto que deve dirigir a forma de cuidar do outro (ALGRANTI, 1993).

Etimologicamente, a palavra decência é relacionada à honra, ao pudor e ao decoro. Mas também se considera a decência como sinônimo de honestidade. Ser decente, então, é ser conveniente (CUNHA, 1989).

Iniciava-se a divisão social do trabalho hospitalar tornando mais nítidos os contornos da separação social de classes. A divisão do trabalho de enfermagem se dá

* Antes desse evento, Florence já estava se tornando conhecida na Inglaterra como uma mulher de força e personalidade notáveis, além de idealista e possuidora de uma capacidade invulgar. Além disso, visitou e instruiu-se em vários lugares considerados como modelos de enfermagem de sua época. NASH, Rosalind. Um esboço da vida de Florence Nightingale. EEAN/UFRJ, 1980. mimeo. p. 3.

** BARNES, Elizabeth. As relações humanas no hospital. Coimbra, Livraria Almedina, 1973. p.81. Coloca que as Enfermeiras estão mais habituadas a que lhes digam o que hão de fazer e como devem conduzir-se do que a terem uma oportunidade oficial de reconhecer e vencer suas angústias.

*** Francisca de Sande era uma viúva baiana, que prestava serviços aos pobres e necessitados. Anna Nery é considerada a primeira Enfermeira brasileira, a partir da assistência prestada aos feridos na Guerra do Paraguai. O seu nome foi dado a primeira Escola de Enfermagem “nightinaleana” no Brasil. PAIXÃO, W. História da Enfermagem. 5 edição, Rio de Janeiro, Júlio C. Reis Livr., 1979.

**** A Santa Casa do Rio de Janeiro foi fundada em1582 por Padre José de Anchieta e administrada pelos jesuítas até a sua expulsão no século 18. FAZENDA, J.V. A Santa Casa da Misericórdia do Rio de Janeiro. Rev. IHGB. V.113, Tomo 69, parte I, 1906.

***** A decência era um sinônimo de honra, de um bem maior de todas as mulheres castas. ALGRANTI, Leila. M. Honradas e devotas: mulheres da colônia. Rio de Janeiro, José Olympio Ed. Brasília, Edunb, 1993. 
como uma divisão do trabalho médico e das irmãs de caridade, isto é, as tarefas manuais e aquelas que envolvem cuidados com o corpo nu passam a ser atribuição da enfermagem, porém sob a hegemonia das irmãs de caridade e da prática médica.

Embora tenham decorrido quase dois séculos, em muitos lugares a assistência de enfermagem ainda é subsidiada pelo trabalho e pelo pensamento médico. A disciplina e o controle são inerentes à enfermagem. As Enfermeiras estão habituadas a cumprir ordens, a esperar que lhes digam o que fazer e como devem conduzir-se reforçando o tripé da ação estabelecido por FOUCAULT (1982) que alia o hospital à instituição militar, isto é, a disciplina, o controle e a anotação constante.

Estes estereótipos imprimem na(o) enfermeira(o) "qualidades" como obediência, humildade, respeito à hierarquia e outros, que são desejados, esperados e exigidos muitas vezes desde o início da formação universitária. Na vida profissional a cobrança por este tipo de comportamento permanece nas figuras do paciente, família e equipe multiprofissional (GERMANO, 1984); (SILVA, 1986).

Em estudo relativo à influência da formação familiar e social na escolha e exercício da enfermagem, PADILHA (1990) detectou que a ideologia presente nos papéis femininos de cuidar dos enfermos, ser carinhosa com aqueles que precisam e servir ao próximo são características presentes no "espírito de servir". Estas foram consideradas no estudo como características esperadas e determinantes na escolha da profissão de enfermagem, como também no trabalho das religiosas.

Ao analisar e refletir sobre os diferentes aspectos que se referem ao "dever ser" da Enfermeira, reforçado pelos discursos médicos, facilmente podemos relacionálos ao que se "espera" da mulher, isto é, que seja cumpridora dos deveres, devotada, honesta, disciplinada e abnegada. Este estudo não pretende ser conclusivo e nem tampouco excludente de outras influências recebidas pelas enfermeiras no desenvolvimento de suas ações cotidianas, porém acreditamos que são elos de uma mesma corrente que representam papéis historicamente construídos e nos quais os médicos tiveram também a sua importância e isto precisa ser reconhecido e discutido para a compreensão da realidade atual.

\section{O PODER DISCIPLINADOR DAS PALAVRAS}

O século XIX assinala para o Brasil o início de um processo de transformação política e econômica que atinge igualmente o âmbito da saúde como um todo e da Medicina em particular, inaugurando duas de suas características, que não só têm vigorado até o presente, como têm-se intensificado cada vez mais: a penetração da medicina na sociedade, que incorpora o meio urbano como alvo da reflexão e da prática médicas, e a situação da medicina como apoio científico indispensável ao exercício do poder do Estado.

No Brasil a implantação da "polícia médica" se voltou para o saneamento dos hospitais e das cidades, como forma de controle dos indivíduos, não de uma forma organizada e totalitária, mas sim, com o controle das virtualidades, o nascimento da periculosidade pelas constantes epidemias que invadiam a corte e com ela a prevenção.

$\mathrm{O}$ objeto da medicina transforma-se com um enfoque na saúde dos indivíduos e não mais a ação direta e lacunar sobre a doença como essência isolada e específica que move o projeto médico. $\mathrm{O}$ "médico político" deve dificultar ou impedir o aparecimento da doença, lutando, ao nível de suas causas, contra tudo o que na sociedade pode interferir no bem-estar físico e moral.

\begin{abstract}
“A inserção do indivíduo no social, a necessidade de conhecer o meio e agir para proteger o indivíduo de um perigo ao mesmo tempo médico e político não significa porém que a medicina sai do seu campo próprio de ação. Se a sociedade, por sua desorganização e mal funcionamento, é causa de doença, a medicina deve refletir e atuar sobre seus componentes naturais, urbanísticos $e$ institucionais visando a neutralizar todo perigo possível" (MACHADO, 1978, p. 152).
\end{abstract}

Os dois aspectos fundamentais de medicina social, que já se encontravam explicitados como os dois principais objetivos da Sociedade de Medicina - a higiene pública e a normalização da medicina recebem neste momento sua formulação institucional.

A medicina social preocupa-se com o saneamento das cidades e das instituições, entre elas o Hospital. O projeto de medicalização das instituições baseia-se em dois princípios: a localização central dos hospitais no espaço urbano e a desorganização de seu espaço interno.

Com a institucionalização da clínica as relações de poder se estabelecem a partir da prática médica, e permanecem até hoje, determinando e imprimindo sua marca no dia a dia das relações sociais.

A enfermagem é uma profissão de mulheres e, como tal, no processo histórico de sua evolução, sempre foi considerada como elemento de apoio, sempre subordinado e nunca como agente principal das ações sociais.

A tomada de poder pelo médico se manifesta no ritual da visita aos pacientes internados. 
"É um desfile quase religioso em que o médico, na frente, vai ao leito de cada doente seguido de toda a hierarquia do hospital: assistentes, alunos, enfermeiras, etc. Essa codificação ritual da visita, marca o advento do poder médico, devendo ser o mesmo anunciado por uma sineta, e a enfermeira deve estar na porta com um caderno nas mãos devendo acompanhar o médico quando ele entrar"(FOUCAULT, 1982, p. 110).

Este caráter relacional de poder se repete até os dias de hoje em muitas instituições hospitalares. As histórias de resistências silenciosas ou não, oferecidas pelas enfermeiras a estas relações são excluídas do discurso que até recentemente foi escrito por homens e muitas vezes médicos.

Ao pensar as relações de poder, FOUCAULT (1982) nos remete a uma técnica específica de poder que ele chamou de disciplina ou poder disciplinador. Para descrever os princípios do uso da disciplina como técnica de poder, toma como exemplos o exército e a escola, os quais se adequam à forma como a igreja e a enfermagem utilizam a disciplina. A disciplina é antes de tudo a análise do espaço, isto é, a individualização pelo espaço.

O poder disciplinador das palavras refletindo na prática de enfermagem e na criação e perpetuação de seus estereótipos pode ser visualizado e compreendido através da análise dos discursos médicos sobre o dever ser da enfermeira:

"São auxiliares discretas, mais de passos e ações que de palavras, fiéis ao conselho de São Francisco de Salles: o barulho não pratica o bem, o bem não faz barulho".(RIBEIRO, 1956)*.

"Zeladoras da ordem, do respeito e do asseio nas enfermarias da misericórdia”(RIBEIRO, 1956, p. 47)*.

O discurso médico modela o comportamento esperado e estereotipado das enfermeiras, ou melhor, sua representação, não de forma totalitária, mas contribuindo para explicar a representação deste comportamento submisso e silencioso do cotidiano das enfermeiras.
Neste "dever ser" da enfermeira, modelado ao longo dos anos, configuram-se características de qualidades que ela deve ter para ser considerada uma "boa" enfermeira. Isto pode ser evidenciado no discurso proferido em 1923 para as alunas da Escola de Enfermagem Anna Nery, o qual dizia:

\begin{abstract}
"há poucos dias um dos médicos perguntoume acerca de uma aluna; perguntaram-me se era orgulhosa, retraída, pois não podiam decifrá-la. Pedi-lhes uma explicação de sua maneira de portar-se e replicaram que era atenciosa, cortez, mas que somente respondia sim ou não às suas perguntas, indagando quando não compreendia; que não conversava com os médicos, mas que silenciosa fazia seus deveres... eles a respeitavam e disseram que era o tipo de enfermeira que gostariam de ter se estivessem procurando uma boa executiva"**.
\end{abstract}

Silenciosa, cortês e cumpridora dos seus deveres, poderia haver alguém com melhores características para servir ao médico?

O silêncio é uma marca distintiva da enfermeira no imaginário social, que freqüentemente é representada no gesto que o simboliza com o dedo indicador sobre a boca, solicitando silêncio, em cartazes divulgados há décadas pela indústria de equipamentos e materiais hospitalares e presentes em quase todas as enfermarias dos hospitais brasileiros.

Esse pode ser discutido de duas formas: o silêncio pela omissão (submissão) e acato às ordens médicas, como também o silêncio que domina pelas ações e não pelas palavras. É o poder silencioso, porém decisivo. Em ambos os casos pode ser colocada a semelhança entre o trabalho desempenhado pelas enfermeiras e pelas irmãs de caridade.

No entanto devemos considerar a forma de poder (formal porém silencioso) por elas exercido, já que detinham o controle das finanças e a direção dos serviços administrativo, médico e de enfermagem e parte do serviço religioso $* * *$ da Santa Casa.

"A enfermeira constitui a grande força vigilante, incansável, contínua, penetrante e

* RIBEIRO, Lourival. A luta contra a Tuberculose no Brasil. (apontamentos para sua História). Rio de Janeiro, 1956. O autor é médico, escreveu vários livros sobre a História da Medicina e a Higiene no Rio de Janeiro, tais como, Medicina no Brasil colonial.

** O discurso foi encontrado no Centro de Documentação da Escola de Enfermagem Anna Nery, com a data de 1923, porém sem autoria. Provavelmete foi proferido pela diretora da escola à época Senhora Louise Kenninger.

*** Assistência Pública e Privada no Rio de Janeiro (Brasil) História e Estatística. Commemoração do Centenário da Independência Nacional. Typografia do <<annuário do Brasil〉> Rio de Janeiro, 1922, pp.529-531. 
inquebrantável, nos serviços sanitários modernos. Em nenhuma profissão, a mulher poderá dar mais de sí mesma, em benefício da coletividade sofredora" (PAULA, 1940, p. 162).

O ideário de abnegação e de doação permeiam o discurso médico e colocam a enfermeira quase que como uma Super-Mulher, "incansável" e disposta a fazer da sua vida, uma vida de cuidar do outro, esquecendo-se de si mesma e das suas próprias necessidades como mulher, como pessoa e como cidadã.

Estas prescrições, que modelaram o comportamento das enfermeiras e foram difundidas através dos anos, têm funcionado como o passaporte necessário à qualquer instituição que as desejasse como elementos constitutivos de seu pessoal.

\section{“...Para que as enfermeiras de Saúde Pública estejam em condições de desempenhar os complexos encargos, que as tornam mensageiras do bem, necessário que seu espírito atinja pela educação e pela instrução, a um nivel que lhes permita fazer-se respeitar, por suas qualidades morais e tornar-se obedecidas pelas demonstrações de suas aptidões técnicas ( ).” (CUNHA, 1923)}

O discurso médico estabelecia o modelo desejado para o preparo daquelas enfermeiras que iriam difundir o ideário da Saúde Pública brasileira, e este ideal de comportamento molda as ações de enfermagem até os dias de hoje influenciando o pensamento e o imaginário social e das próprias enfermeiras com relação ao que se espera de uma Enfermeira de qualidade, propiciando a construção de estereótipos.

A preocupação com a disciplina implica em um registro contínuo. Anotação do indivíduo e transferência da informação de baixo para cima, de modo que, no cume da pirâmide disciplinar, nenhum detalhe, acontecimento ou elemento disciplinar escape a esse saber.

Este tripé controle do espaço/tempo, a vigilância constante e o registro contínuo são demarcadores das ações de enfermagem hospitalar, desde o século XIX, entre as irmãs de caridade/praticantes de enfermagem e os médicos/provedores, e são pistas que ajudam a entender a disciplina como técnica de exercício de poder.

"A obediência e o respeito aos superiores e às ordens deles emanadas dão às enfermeiras uma confirmação valiosa de que estão na altura de exercer essa elevada missão." (SANTOS, 1907)

"O seu dever é executar as ordens médicas, notificar ao médico inteligentemente os sintomas e condições encontrados." (PARSONS,1929)

O momento histórico das disciplinas é o momento em que nasce uma arte do corpo humano, que visa não unicamente o aumento de suas habilidades, nem tampouco aprofundar sua sujeição, mas a formação de uma relação que no mesmo mecanismo o torna tanto mais obediente quanto mais útil, e vice-versa, de acordo com a situação que se apresente (FOUCAULT, 1987).

A forma de cuidar do outro na enfermagem pode ser comparada com a ideologia do trabalho nas ordens religiosas, que vivem para "servir a Deus através dos homens"e se evidencia também na formação da associação das irmãs de caridade de São Vicente de Paula, que exigiam "boas moças, mostrando desejo de servir os pobres e instrui-las nos exercícios da piedade" (CASTRO, 1936).

"Ser amável e delicada, desvelada, corajosa e disposta a suportar sacrifícios e dissabores, por vezes inevitáveis na presença de enfermos, cujas impertinências são sempre justificáveis" (SANTOS, 1907, p. 13).

"Cada aluna tem um sentimento religioso, cada aluna está seguindo os passos de Cristo, levando o evangelho de higiene e saúde a humanidade sofredora; deve então ser um exemplo do espírito de servir(...) é necessário muita coragem para ser boa enfermeira” KIENINGER*.

Estes discursos proferidos por um médico e por uma enfermeira têm em comum a colocação da enfermagem como uma profissão de sacrifícios, de amor extremo ao próximo, da obrigatoriedade do sofrimento para exercê-la, bem como do sentimento cristão que deve envolver suas ações. É como se cada aluna ou enfermeira tivesse que sofrer no calvário da profissão para obter o descanso eterno.

Além disso, evidenciam claramente que o discurso médico influencia e de certo modo ajuda a construir o discurso das enfermeiras do início do século, as "nightingaleanas".

Outro aspecto que vem à tona é o discurso da

\footnotetext{
* KIENINGER, C.L. Discurso "analisando o ideal”, 1923
} 
impessoalidade, da necessidade de afastamento de qualquer contato íntimo e individual, no sentido de mostrar-se e discutir-se como seres humanos que sentem e pensam algo além do cuidado que prestam. Até os dias de hoje, existem professoras de enfermagem exigindo que suas alunas e alunos mantenham um distanciamento de alunos de outras áreas no cotidiano hospitalar e punindo-as (os) caso isso ocorra. A distância e a impessoalidade favorecem o controle, inibem a emoção e mais facilmente transformam gente em máquina, robotizando e massificando a arte de cuidar.

\section{"As enfermeiras tem orgulho na nitidez de seus uniformes, não há conversas, nem chamadas, de um lado da enfermaria ao outro. Não há discussão de afazeres e negócios pessoais e se algum médico fizer perguntas pessoais, a resposta será "não posso dizer" KIENINGER*.}

A presença médica no espaço hospitalar disciplinando e formando o comportamento das enfermeiras pode ser evidenciada nos discursos a seguir, que mostram a participação dos médicos inclusive na seleção e admissão das Alunas à Escola de Enfermeiras do Departamento Nacional de Saúde Pública, a qual foi instituída como "escola padrão" a partir de 1931**.

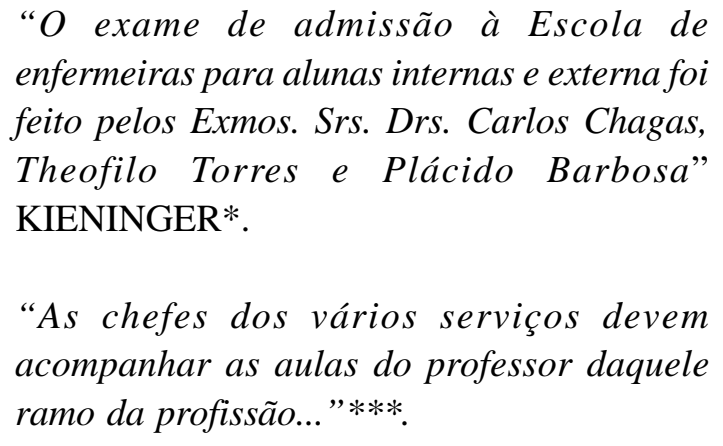

A hegemonia médica em relação ao direcionamento do ensino teórico-prático de enfermagem da primeira escola moderna no Brasil influenciou sobremaneira a própria condução das relações entre os profissionais de saúde, reafirmando o poder da prática médica sobre a de enfermagem, garantindo a supremacia e dominação de uma sobre outra, e sendo incutida no ideário das enfermeiras.

Embora, atualmente, esta trama de relações esteja se transformando numa prática igualitária, em que os profissionais de saúde trocam experiências de uma forma menos diretiva por parte do médico, ainda podemos encontrar nos pequenos centros esta enfermagem submissa, dirigida e determinada pelo discurso médico, bem como o ensino de enfermagem sendo propagado de acordo com o modelo biomédico, como uma equiparação à prática médica.

\section{CONSIDERAÇÕES FINAIS}

Rememorar essas particularidades do cotidiano das relações Enfermeira/Médico no ambiente hospitalar e de ensino tem como idéia básica mostrar a grande influência que as idéias, experiências e métodos de organização e execução dos médicos exercia sobre as novas Enfermeiras que se formavam no Brasil.

No passado e no início deste século, o poder disciplinador das palavras contidas no discurso médico auxiliou na forma como foi modelado e docilizado, com a ajuda da Igreja, o comportamento daquelas que eram eleitas para cuidar dos doentes e manter a organização do espaço hospitalar.

É a formação profissional da enfermeira modelada pelo discurso médico, construindo imagens estereotipadas e demarcadas pelas enfermeiras "nightingaleanas", e que foram se constituindo em modelos de comportamento desejado e até mesmo esperado pela equipe de saúde e pela sociedade a quem prestamos serviço.

As características marcantes no comportamento da enfermeira eram o silêncio, a cortesia, a obediência e o espírito de servir ao próximo sem esperar recompensa. A enfermeira foi se configurando como o detalhe branco e silencioso, presente e indispensável, distante e impessoal, contida e contendo, obediente e servil - mulher ocupando o espaço público para o trabalho, mas ainda privada da liberdade de ser, fazer e sentir como desejasse.

\footnotetext{
* KIENINGER, C.L. Discurso "analisando o ideal”, 1923

** A escola Anna Nery foi elevada à escola oficial padrão, pela qual todas as demais escolas deveriam se orientar, a partir do decreto 20109/31, que regulava o exercício de enfermagem no Brasil..Isto só foi modificado com a promulgação da primeira lei do Ensino de Enfermagem, a Lei $n^{\circ}$ 775/49. CARVALHO, Anayde C. Associação Brasileira de Enfermagem. 1926 - 1976. Documentário. Brasília, DF, 1976

*** Resumo da Reunião das Chefes de Enfermagem realizada a 8 de julho de 1935
} 
NURSE - THE CONSTRUCTION OF A BEHAVIOR MODEL BASED ON THE MEDICAL DISCOURSE OF THE BEGINNING OF THE CENTURY

The purpose of this study is to trace a parallel between the medical discourse content and the expected and stereotyped nurses behavior at the beginning of the twentieth century. It is a historic-social approach in which authors analysed the speeches used by nurses and physicians at nursing and medicine schools. The analysis of the physicians discourse compared to nurses discourse revealed the formation of a mentality shaped by the medical power that wanted them "holy" and servile.

KEY WORDS: nursing, history, Hospital "Santa Casa de Misericórdia” at Rio de Janeiro

\section{ENFERMERA - LA CONSTRUCION DE UN MODELO DE COMPORTAMIENTO A PARTIR DE LOS DISCURSOS MÉDICOS}

El objetivo es trazar un paralelo entre el contenido de los discursos medicos y el comportamiento esperado y esteriotipado de las enfermeras del inicio del siglo. Tiene un abordaje hsitórico-social que utilizó como fuentes los discursos médicos y de enfermeras proferidos en las escuela de enfermagen y de medicina. El analisis de los discursos médicos comparada a los discursos de las enfermeras reflejan la formación de una mentalidad intrinsecamente modelada y socilizada por el poder médico que las deseaba santas y sometidas y sirvientes.

TÉRMINOS CLAVES: enfermería, historia, santa casa de misericordia de Rio de Janeiro

\section{REFERÊNCIAS BIBLIOGRÁFICAS}

01. ALGRANTI, L.M. Honradas e devotas: mulheres da colônia. Condição feminina nos conventos e recolhimentos do sudeste do Brasil, 1750-1822. Rio de Janeiro: José Olympio, 1993.

02. CASTRO, J.C.M. Vida de Luiza de marillac fundadora das Irmãs de caridade. Petrópolis, Vozes, 1936.

03. CUNHA, A.G.da. Dicionário etimológico nova fronteira da lingua portuguesa. $2^{\mathrm{a}}$ ed. Rio de Janeiro: Nova Fronteira. 1989.

04. CUNHA, R.F. Discurso proferido na Academia de Medicina do Congresso Internacional de Higiene Infantil. Rio de Janeiro, 1923.

05. DIAS, M.O.L.S. Novas subjetividades na pesquisa histórica feminista: uma hermenêutica das diferenças. Rev. Estudos Feministas, v. 2, p. 373-382, 1994.

06. FOUCAULT, M. Microfísica do poder. 3. ed. Rio de Janeiro: Graal, 1982.

07. - Vigiar e punir. 6. ed. Petrópolis: Vozes, 1987.

08. GERMANO, R.M. Educação e ideologia da enfermagem brasileira. São Paulo: Cortez, 1984.

09. MACHADO, R. et al. Danação da norma: a medicina social e constituição da psiquiatria no Brasil. Rio de Janeiro: Graal, 1978.

10. PADILHA, M.I.C.S. O resgate das raízes: A influencia da formação familiar e social na escolha e exercício da Enfermagem. Tese de Livre-Docência defendida na Escola de Enfermagem Alredo Pinto/ UNIRIO, 1990.
11. PAIXÃO, W. História da enfermagem. 5. ed. Rio de Janeiro: Júlio C. Reis Livraria, 1979.

12. PARSONS, E. A enfermagem moderna no Brasil: exposições e relatórios. Rio de Janeiro, 19221929.

13. PAULA, A.de. A assistência sanitária no Brasil e a Enfermeira nos Serviços de saúde. São Paulo, Anais, v. 4, p. 162, out. 1940.

14. RIBEIRO, L. A luta contra a Tuberculose no Brasil. (apontamentos para sua história), Rio de Janeiro, 1956. p. 47.

15. SALMON, P. História e crítica. Coimbra: Almedina, 1979.

16. SILVA, G.B. Enfermagem profissional: análise crítica. São Paulo: Cortez, 1986.

\section{OUTRAS FONTES}

Instituto Histórico e Geográfico Brasileiro/Centro de Documentação da Escola de Enfermagem Anna Nery

01. ALCÂNTARA, G. A enfermagem moderna como categoria profissional: obstáculos à sua expansão na sociedade brasileira. Ribeirão Preto: USP/EERP, 1966.

02. AZEVEDO, M.de. A faculdade de Medicina do Rio de Janeiro - Notícia Histórica. Rev.Trim. do IHGEB Tomo XXX - Parte segunda, p. 397-398, 1867.

03. BARNES, E. As relações humanas no hospital. Coimbra: Livr. Almedina, 1973. 
33

04. BRASIL - RIO DE JANEIRO. Assistência pública e privada no Rio de Janeiro. História e estatística. Comemoração do Centenário da Independência Nacional. Tipografia do anuário do Brasil, Rio de Janeiro, 1922. pp. 320-528.

05. CARVAlHO, A.C. Associação Brasileira de Enfermagem. 1926-1976. Documentário. Brasília, DF, 1976.

06. FAZENDA, J.V. A Santa Casa da Misericórdia do Rio de Janeiro. Rev. IHGB. v.113, Tomo 69, parte I, 1906.

07. FOUCAULT, M. A arqueologia do saber. 4. ed. Rio de Janeiro: Forense Universitária, 1995. Cap. 2 e 3 .
08. NASH, R. Um esboço da vida de Florence Nightingale. EEAN/UFRJ, 1980. mimeo

09. Primeiro Relatório Narrativo da Escola de Enfermagem Anna Nery. /Discurso encontrado no Centro de Documentação da Escola de Enfermagem Anna Nery, com a data de 1923, porém sem autoria, provavelmente elaborado pela Diretora Miss Clara Louise Keninger./

10. RIBEIRO, L. Medicina no Brasil colonial. Rio de Janeiro, (GB), 1971. p.43-45.

11. SANTOS, G. Livro do enfermeiro e da enfermeira. Rio de Janeiro, Typ. do Jornal do Com., 1916.

12. SANTOS FILHO, L. História geral da medicina brasileira. v. 1 e 2, São Paulo: Hucitec/ Edusp, 1991. 